
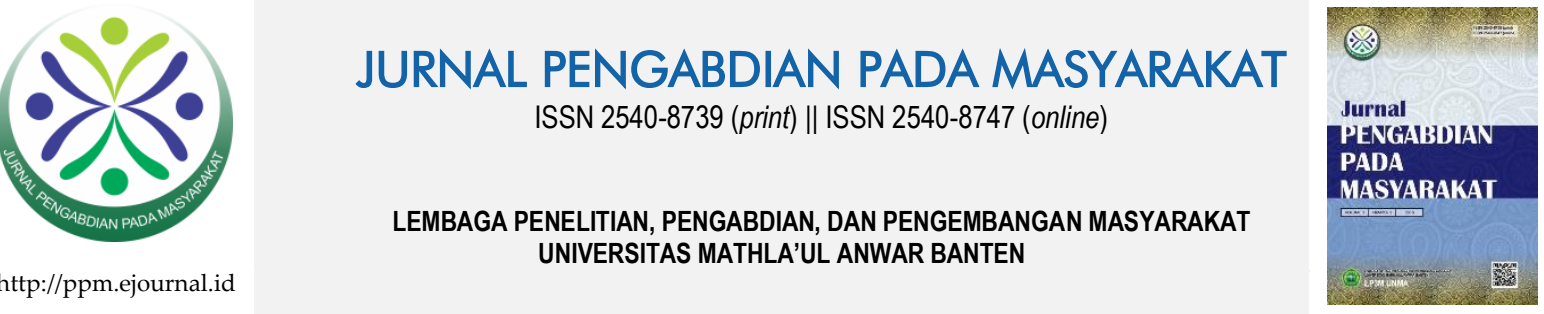

\title{
Upaya Meningkatkan Deteksi Dini Kanker Payudara di SMKN 1 Cijulang Kabupaten Pangandaran
}

Muhammad Hasan Bashari ${ }^{1 *}$, Hermin Aminah Usman², Dika Widia Nur Azizah ${ }^{3}$, Defi Ardia Pramesti ${ }^{4}$, Arima Kurnia Sari Dewi Nurcahyani ${ }^{4}$, Atika Hana Ilyasa ${ }^{4}$, Nadifah Diana Zalia ${ }^{5}$, Alexander Kurniawan Sidiq ${ }^{5}$, Risqi Dwi Putra ${ }^{6}$, Dikri Muhammad Ihsan ${ }^{6}$, Lala yuliani ${ }^{7}$, Dwi Andini ${ }^{8}$, Naura Mardhiyah ${ }^{8}$ Putri Halleyana ${ }^{1}$, Titing Nurhayati ${ }^{1}$, Astrid Feinisa Khairani ${ }^{1}$, Dimas Erlangga Luftimas ${ }^{9}$, Rani Septriana ${ }^{10}$

\author{
${ }^{1}$ Departemen Ilmu Kedokteran Dasar, Fakultas Kedokteran, Universitas Padjadjaran \\ ${ }^{2}$ Departemen Patologi Anatomi, Fakultas Kedokteran, Universitas Padjadjaran \\ ${ }^{3}$ Program Studi Biologi, Fakultas Matematika dan Ilmu Pengetahuan Alam, Universitas Padjadjaran \\ ${ }^{4}$ Program Studi Kedokteran, Fakultas Kedokteran, Universitas Padjadjaran \\ ${ }^{5}$ Program Studi Manajemen Produksi Media, Fakultas Ilmu Komunikasi, Universitas Padjadjaran \\ 6Program Studi Ilmu Peternakan, Fakultas Peternakan, Universitas Padjadjaran \\ ${ }^{7}$ Program Studi Keperawatan, Fakultas Keperawatan, Universitas Padjadjaran \\ ${ }^{8}$ Program Studi Ilmu Komunikasi, Fakultas Ilmu Komunikasi, Universitas Padjadjaran \\ ${ }^{1}$ Departemen Ilmu Kedokteran Dasar, Fakultas Kedokteran, Universitas Padjadjaran \\ ${ }^{9}$ Departemen Ilmu Kesehatan Masyarakat, Fakultas Kedokteran, Universitas Padjadjaran \\ ${ }^{9}$ Departemen Ilmu Bedah, Fakultas Kedokteran, Universitas Padjadjaran
}

\begin{tabular}{l}
\hline ARTICLE INFO \\
\hline Article History: \\
Received 05.09 .2018 \\
Received in revised \\
form 11.11 .2018 \\
Accepted 30.11 .2018 \\
Available online \\
21.12.2018
\end{tabular}

\begin{abstract}
The high mortality rate of breast cancer (BC) patients in Indonesia is associated with conditions of most patients come to doctor in an advanced stage of BC. This is due to low $\mathrm{BC}$ awareness of Indonesian women. This community service program (PPM) is intended to increase knowledge of adolescent women about early detection of BC. This action was conducted by BC awareness workshop to 114 female students of Vocational High School (SMK) 1 Cijulang, Pangandaran district, West Java. The profile of participants showed that $64 \%$ of participants are 17 years old and mostly from Cijulang and Cimerak sub-districts. In addition, the majority of participants were not aware of $\mathrm{BC}$, indicated by lack of knowledge of $\mathrm{BC}$ signs and symptoms $(97 \%)$, and low confident of doing breast self-examination (BSE) $(30 \%)$. Moreover, there were $7 \%$ of participants were smoking which is known to be one of the major risk factors for BC. These findings point out for conducting a program for increasing $\mathrm{BC}$ awareness among students. The program was managed by mini-lecture that focuses on $\mathrm{BC}$ risk factors, $\mathrm{BC}$ early detection and BSE (SADARI) using videos and simulation on a mannequin. This program was expected to have an impact on their families, indirectly. Ultimately, this will increase the finding of new cases of $\mathrm{BC}$ which will increase their life expectancy.
\end{abstract}

Keywords: Breast Cancer, Breast Self-Examination, Early Detection.
DOI: $10.30653 / 002.201832 .87$
This is an open access article distributed under the terms of the Creative Commons Attribution 4.0 International License, which permits unrestricted use, distribution, and reproduction in any medium, provided the original work is properly cited. @ 2018 Muhammad Hasan Bashari et al.

\footnotetext{
* Corresponding author: Divisi Farmakologi dan Terapi, Departemen Ilmu Kedokteran Dasar, Fakultas Kedokteran, Universitas Padjadjaran; Jalan Professor
} Eyckman No.38, Bandung 40161 Indonesia, email: bashari@unpad.ac.id 


\section{PENDAHULUAN}

Kanker menjadi salah satu penyebab kematian utama di dunia (Torre, Siegel, Ward, \& Jemal, 2016). Kanker payudara (KP) merupakan jenis kanker dengan insidensi dan penyebab kematian tertinggi pada wanita baik di dunia maupun di Indonesia (Fitzmaurice et al, 2015; Kementerian Kesehatan, 2015).

Terdeteksinya KP pada stadium awal meningkatkan keberhasilan terapi KP (Cotran et al, 2015; Soerjomataram, Louwman, Ribot, Roukema, \& Coebergh, 2008). Namun sayangnya, kebanyakan wanita dengan KP datang berobat dan terdiagnosis saat stadium lanjut (Ng et al, 2011; Rahmatya, Khambri, \& Mulyani, 2015). Hal ini menurunkan efektivitas penanganan dan meningkatkan resiko kematian KP (Cossio et al, 2015; Soerjomataram et al, 2008). Salah satu sebab terlambatnya penanganan kasus KP adalah rendahnya kewaspadaan wanita akibat rendahnya pengetahuan terhadap KP (Mardela, Maneewat, \& Sangchan, 2017; Sathian et al, 2014). Pengetahuan memengaruhi seseorang dalam bertindak, dalam hal ini memengaruhi seseorang untuk memeriksakan, memengaruhi ketaatan terhadap penatalaksanaan, dan juga dalam mengatur gaya hidup (Sunaryo, 2002). Selain itu, pengetahuan mengenai hal terkait juga mempengaruhi kewaspadaan seseorang (Sunaryo, 2002). Upaya meningkatkan pengetahuan dapat dilakukan melalui penyuluhan pada mayarakat (Rukmana \& Mulyani, 2016)

Walaupun risiko terjadinya kanker payudara pada remaja masih kecil namun perjalanan hidup mereka masih panjang, sehingga perlu dibekali dengan informasi tentang kanker payudara dan upaya deteksi dini kanker payudara. Selain itu, mereka biasanya masih tinggal bersama orang tua, sehingga mungkin juga dapat menjadi duta informasi bagi keluarga mereka. Dengan demikian, kami memandang perlu untuk meningkatkan pengetahuan dan kewaspadaan para remaja putri mengenai KP. Harapannya selain akan meningkatkan kewaspadaan mereka secara pribadi juga dapat berdampak pada lingkungan sekitar mereka.

\section{METODE PELAKSANAAN}

Untuk meningkatkan pengetahuan tentang deteksi dini penyakit kanker payudara, kegiatan Pengabdian Pada Masyarakat (PPM) telah dilakukan dengan populasi target adalah seluruh siswi Sekolah Menengah Kejuruan (SMK) Negeri 1 Cijulang. Kegiatan ini berupa pelatihan kepada 114 siswi SMK 1 Cijulang, kabupaten Pangandaran, propinsi Jawa Barat. Peserta pelatihan dibagi menjadi 4 kelas, yang masing-masing kelas terdiri dari maksimal 30 peserta. Pemateri adalah mahasiswa KKN Universitas Padjadjaran dari berbagai fakultas yang sebelumnya telah dilatih dan didampingi oleh 2 dosen pendamping.

Kegiatan diawali dengan pengumpulan data karakteristik peserta pelatihan, serta pengetahuan dasar dan prilaku mereka terkait deteksi dini KP melalui angket online. Selanjutnya kegiatan dilakukan melalui kegiatan pelatihan menggunakan metode ceramah, video simulasi pemeriksaan payudara sendiri (SADARI), brosur serta demonstrasi menggunakan manekin. Materi ceramah berisi tentang bahaya KP serta upaya deteksi dini KP. Video simulasi SADARI digunakan untuk membantu visualisasi peserta kemudian dilanjutkan dengan demonstrasi dan latihan pemeriksaan SADARI menggunakan manekin. 


\section{HASIL DAN PEMBAHASAN}

\section{Karakteristik Peserta Pelatihan}

Peserta kegiatan PPM terutama adalah siswa kelas 10 dan 11 SMK 1 Cijulang, Kabupaten Pangandaran. Mereka berusia 16-19 tahun (Tabel 1). Sekitar 64\% peserta kegiatan PPM adalah berusia 17 tahun (Tabel 1). Mereka berasal dari beberapa kecamatan yang berbeda yang terutama dari kecamatan Cijulang dan Cimerak. Hal ini wajar karena SMK Negeri 1 Cijulang berada di kecamatan Cijulang yang bertetangga dengan kecamatan Cimerak. Diketahui bahwa selain SMK 1 Cijulang, terdapat juga beberapa SMK negeri di kecamatan Pangandaran dan Padaherang. Hal ini menjadi alasan tidak ada peserta pelatihan yang berasal dari kecamatan Kalipucang, Mangunjaya, Padaherang, Pangandaran, Sidamulih.

Tabel 1. Karakteristik Peserta PPM (n=114)

\begin{tabular}{lrr}
\hline Parameter & Frekuensi & Persentase (\%) \\
\hline Usia (tahun) & & \\
\hline 16 & 26 & 22,8 \\
\hline 17 & 73 & 64,0 \\
\hline 18 & 12 & 10,5 \\
\hline 19 & 3 & 2,6 \\
\hline Asal Kecamatan & 3 & 2,6 \\
\hline Cigugur & 47 & 41,2 \\
\hline Cijulang & 38 & 33,3 \\
\hline Cimerak & 4 & 3,5 \\
\hline Langkaplancar & 22 & 19,3 \\
\hline Parigi & 0 & 0,0 \\
\hline Kalipucang, Mangunjaya, Padaherang, & & \\
Pangandaran, Sidamulih & &
\end{tabular}

\section{Kemampuan Menilai Kelainan pada Payudara Sendiri}

Sebelum melakukan pelatihan, peserta diminta untuk mengisi angket online perihal pengetahuan dan prilaku mereka yang berkaitan dengan KP. Data menunjukkan bahwa hampir seluruh siswi tidak tahu tentang tanda dan gejala KP, bahkan 3\% peserta yang mengaku mengetahui tentang gejala KP ternyata sebenarnya mereka hanya mengetahi sebagian kecil dari tanda dan gejala KP (Gambar 1). Kondisi ini serupa dengan hasil penelitian lainnya baik di Indonesia maupun di negara berkembang lainnya bahwa kewaspadaan wanita terhadap KP masih rendah. (Hadi, Hassali, Shafie, \& Awaisu, 2010; Mardela et al, 2017; Sathian et al, 2014).

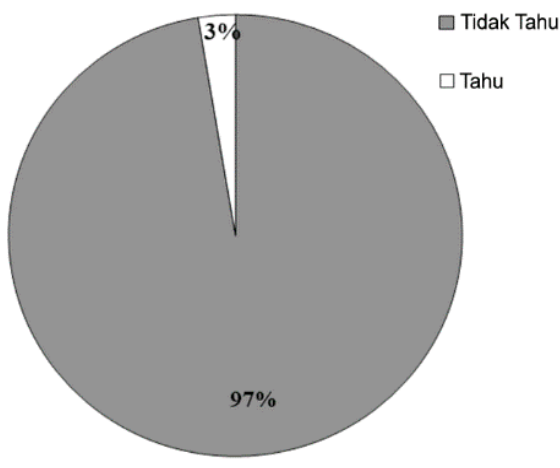

Gambar 1. Grafik Pengetahuan tanda dan gejala kanker payudara 
Selain itu, ternyata sebagian peserta pernah mengetahui tentang pemeriksaan payudara sendiri (SADARI). Namun, sebagian besar tidak yakin dengan pemeriksaan yang mereka lakukan bahkan tidak tahu tentang SADARI (Gambar 2).

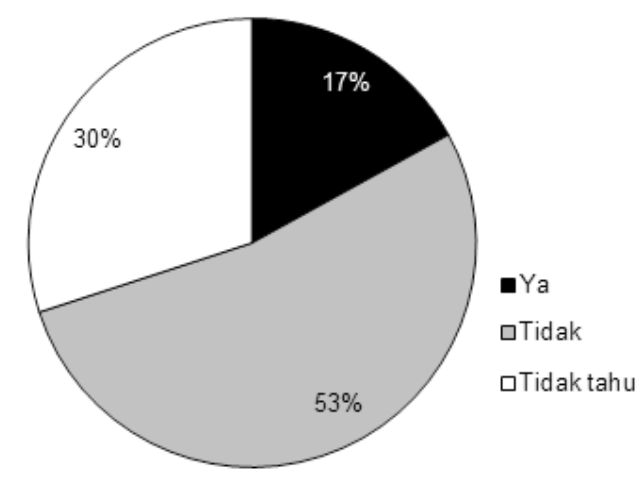

Gambar 2. Grafik Keyakinan terhadap Hasil Pemeriksaan Payudara Sendiri

\section{Kebiasaan Merokok}

Kebiasaan merokok berhubungan dengan sejumlah penyakit dan meningkatkan risiko kejadian kanker payudara di usia muda. Data menunjukkan bahwa terdapat $7 \%$ peserta PPM memiliki kebiasaan merokok (Gambar 3).

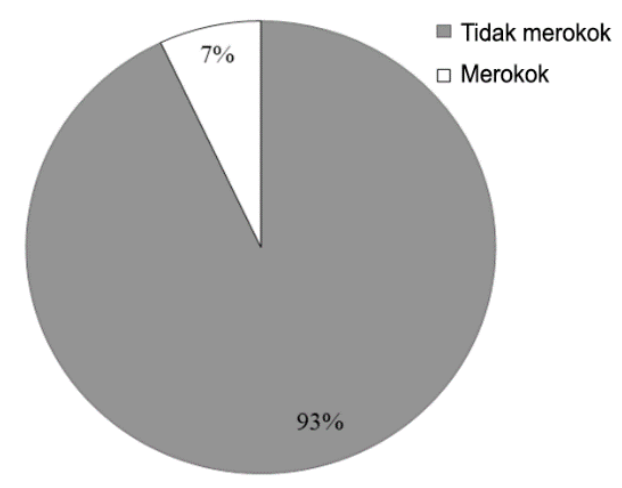

Gambar 3. Grafik kebiasaan merokok

\section{Pelatihan tentang Deteksi Dini Kanker Payudara}

Sesuai dengan temuan di atas maka upaya peningkatan pengetahuan dan kewaspadaan terhadap KP sangatlah beralasan. Kegiatan pelatihan ini dilakukan dengan memberikan ceramah tentang bahaya KP dan kesehatan reproduksi. Untuk meningkatkan retensi informasi yang diberikan maka metode pelatihan juga divariasikan dengan pemutaran video serta demonstrasi menggunakan manekin. Sesi tanya jawab dan latihan merupakan sesi yang cukup menarik karena peserta dapat secara langsung berlatih SADARI pada manikin. Hal ini sekaligus untuk menjawab keraguan mereka tentang cara SADARI. Para peserta pelatihan tampak sangat antusias mengikuti kegiatan ini, yang tercermin dari keaktifan menanggapi pertanyaan maupun mengajukan pertanyaan (Gambar 4). Partisipan juga dapat menyampaikan ulang dan mempraktekkan kembali materi yang sudah disampaikan. 


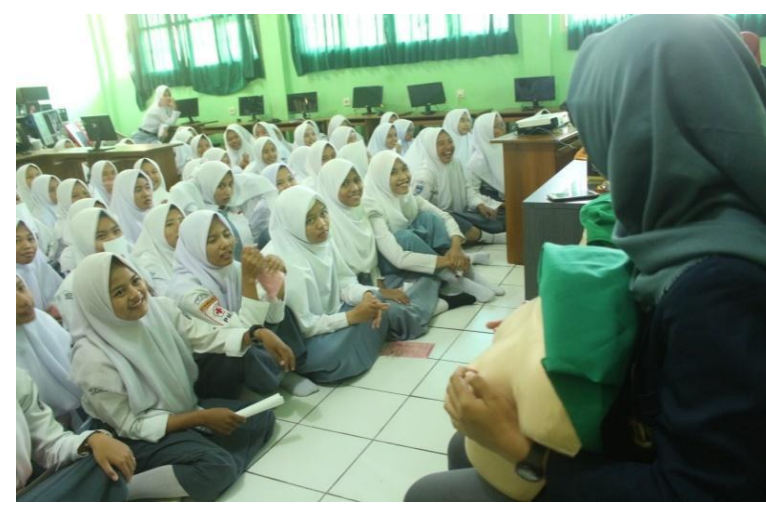

Gambar 4. Demonstrasi SADARI menggunakan Manekin

\section{SIMPULAN}

Tingkat pengetahuan siswi SMK 1 Cijulang, Kabupaten Pangandaran, Jawa Barat tentang deteksi dini KP sangat rendah. Upaya peningkatan pengetahuan tersebut telah dilakukan dengan berbagai metode untuk meningkatkan retensi pengetahuan yang disampaikan. Kegiatan ini diharapkan dapat meningkatkan kewaspadaan pada remaja putri terhadap KP sekaligus diharapkan dapat meningkatkan upaya penemuan kasus dini $\mathrm{KP}$, sehingga lebih mudah ditangaini oleh tenaga kesehatan.

\section{UCAPAN TERIMA KASIH}

Ucapan terima kasih pertama kami sampaikan kepada Kepala dan tim guru SMKN 1 Cijulang yang telah memfasilitasi kegiatan Pengabdian pada Masyarakat (PPM). Terima kasih kami berikan terutama kepada DRPMI UNPAD yang telah memberikan dana PPM ini melalui skema Hibah PPM terintegrasi HIU dan KKN Tahun 2018 no. 2477/UN6.C/PM/2018.

\section{REFERENSI}

Cossio, M. L. T., Giesen, L. F., Araya, G., Pérez-Cotapos, M. L. S., Vergara, R. L., Manca, M., \& Héritier, F. (2015). Harrison's Principles of Internal Medicine-19th Edition. In Harrison's Principles of Internal Medicine-19th Edition Vol. XXXIII (pp. 1842-1843).

Cotran, R., Kumar, V., Robbins, S., Abbas, A. K., Aster, J. C., \& Aster, J. C. (2015). Robbins and Cotran pathologic basis of disease. Philadelphia, PA: Saunders, Ipswich, MA.

Fitzmaurice, C., Dicker, D., Pain, A., Hamavid, H., Moradi-Lakeh, M., MacIntyre, M. F., ... Naghavi, M. (2015). The global burden of cancer 2013. JAMA Oncology, 1(4), 505527.

Hadi, M. A., Hassali, M. A., Shafie, A. A., \& Awaisu, A. (2010). Evaluation of breast cancer awareness among female university students in Malaysia. Pharmacy Practice, 8(1), 2934. 
Kementerian Kesehatan. (2015). Stop Kanker: Situasi Penyakit Kanker. Jakarta Selatan: Pusat Data dan Informasi Kementerian Kesehatan RI. August 11, 2018 from http://www.depkes.go.id/resources/download/pusdatin/infodatin/infodatinkanker.pdf.

Mardela, A. P., Maneewat, K., \& Sangchan, H. (2017). Breast cancer awareness among Indonesian women at moderate-to-high risk. Nursing and Health Sciences, 19(3), 301306.

Ng, C. H., Bhoo Pathy, N., Taib, N. A., Teh, Y. C., Mun, K. S., Amiruddin, A., Evlina, S., Rhodes, A., \& Yip, C. H. (2011). Comparison of breast cancer in Indonesia and Malaysia - A clinico-pathological study between dharmais cancer centre Jakarta and university Malaya medical centre, Kuala Lumpur. Asian Pacific Journal of Cancer Prevention, 12(11), 2943-2946.

Rahmatya, A., Khambri, D., \& Mulyani, H. (2015). Artikel Penelitian Hubungan Usia dengan Gambaran Klinikopatologi Kanker. Jurnal Kesehatan Andalas, 4(2), 478-484.

Rukmana, G. I. T., \& Mulyani, Y. (2016). Penambahan jumlah kader kesehatan dan peningkatan pengetahuan dan pemahaman mengenai kanker pada wanita terutama kanker payudara serta pelatihan pemeriksaan payudara sendiri (SADARI) di desa Cinyasag dan desa Girilaya kecamatan Panawangan kabupaten Ciamis. Dharmakarya: Jurnal Aplikasi Ipteks Untuk Masyarakat, 5(1), 44-46.

Sathian, B., Nagaraja, S. B., Banerjee, I., Sreedharan, J., De, A., Roy, B., ... Menezes, R. G. (2014). Awareness of Breast Cancer Warning Signs and Screening Methods among Female Residents of Pokhara Valley, Nepal. Asian Pacific Journal of Cancer Prevention, 15(11), 4723-4726.

Soerjomataram, I., Louwman, M. W. J., Ribot, J. G., Roukema, J. A., \& Coebergh, J. W. W. (2008). An overview of prognostic factors for long-term survivors of breast cancer. Breast Cancer Research and Treatment, 107(3), 309-330.

Sunaryo. (2002). Psikologi untuk keperawatan (1st ed.). Jakarta: EGC. 